\title{
Integrated Motor Drive Design for Weight Optimization
}

\author{
Benjamin Cheong, Paolo Giangrande, Michael Galea, Pericle Zanchetta, Patrick Wheeler \\ Power Electronics, Machine and Controls (PEMC) Group, \\ University of Nottingham, UK \\ Email: Benjamin.Cheong@ nottingham.ac.uk
}

\begin{abstract}
The More-Electric Aircraft (MEA) concept has been introduced as part of the process of reducing the environmental impact of air travel. Incorporating more electrical systems including motor drives has become increasingly attractive researched. High power density across the complete system is a key factor in the realization of this technology. This paper considers a motor drive sizing procedure with a focus on optimizing the main weight contributors which are identified as the electrical machine, grid input filters and converter cooling system. A multi-level integrated optimization method is then proposed, followed by an example of its application incorporating the sizing procedure above. Comparison of results between single-level optimizations and multi-level optimizations are then presented. Finally, this paper presents the software validation of the sizing functions performed using different multi-physics software.
\end{abstract}

\section{INTRODUCTION}

AC motor drives are commonly selected for electromechanical actuation in MEA concepts and applications. With an increased focus in carbon emission reduction across the globe, MEA concepts are continuing to draw substantial research attention especially from industry. In MEA concepts, the employment of motor drives play a key role in replacing existing pneumatic and hydraulic systems. Indeed motor drives allow to achieve high power density and satisfactory efficiency, which contribute to reducing $\mathrm{CO} 2$ emissions. [1].

The main components of a motor drive are an electrical machine, a power converter and a control unit. The power converter is connected to the grid through filters. The design for minimal weight while still meeting the required output performance can be posed as an optimization problem. Traditionally, due to its complexity and multi-disciplinary nature, power converter and electrical machine are separately designed and individually optimized. The integration of these separately designed components and joint functionality is then ensured by imposing legacy interface standards at points of common coupling. These standards are typically set as constraints for system design variables and result in non-optimum overall systems [2]. Most existing literature in drive optimization research has focused on optimizing either the power converter or machine as decoupled and standalone systems. For instance, [3] discussed the application of random heuristic methods for the weight optimization of a Permanent Magnet Synchronous Machine (PMSM) where as [4], [5] focused on the design optimization of a Silicon Carbide power converter. There is however noticeably less attention targeting the integrated optimized design of a full motor drive system.

For integrated optimizations, it is important to first develop models of the motor drive that capture subsystem interactions between power converter and electrical machine [6]. Due to its complexity and number of non-linear or discrete variables, optimizations of such nature are typically based on random heuristics methods and their convergence is not always ensured. For example, in [7], an integrated motor drive optimization using Particle Swarm Optimization (PSO) with seven design variables is described for a fault-tolerant permanent magnet motor drive.

A multi-level integrated optimal design method has recently been proposed in [8]. The proposed strategy performs the optimization at two separate levels to achieve better convergence. However, a clear and systematic method in the formulation of the proposed multi-level problem was not mentioned.

To model a complex power system, a four level modeling paradigm has been proposed in [9]. The four level modeling paradigm is shown in Figure 1. This approach systematically groups the system performance or parameters into individual layers where they are separately modeled based on their differences in dynamic frequencies. The optimization method introduced in this work is based on the four level paradigm reported in Figure 1, hence it exploits the multi-level approach. This approach enables a systematic formulation of multi-level optimization problems for complex power systems such as motor drives.

In Section II, the considered motor drive topology is presented. Section III discusses the procedures and sizing functions for the design of power converter including filters and electrical machine. These functions are tailored for use in an integrated optimization. The proposed multi-level integrated optimization approach is explained in Section IV along with a study case example. Further the comparison with singlelevel optimizations are shown. Finally in Section V, a software validation of the sizing functions using multi-physics tool is presented.

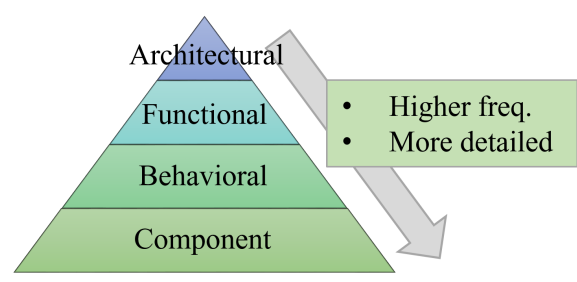

Fig. 1. 4-Level modeling paradigm 


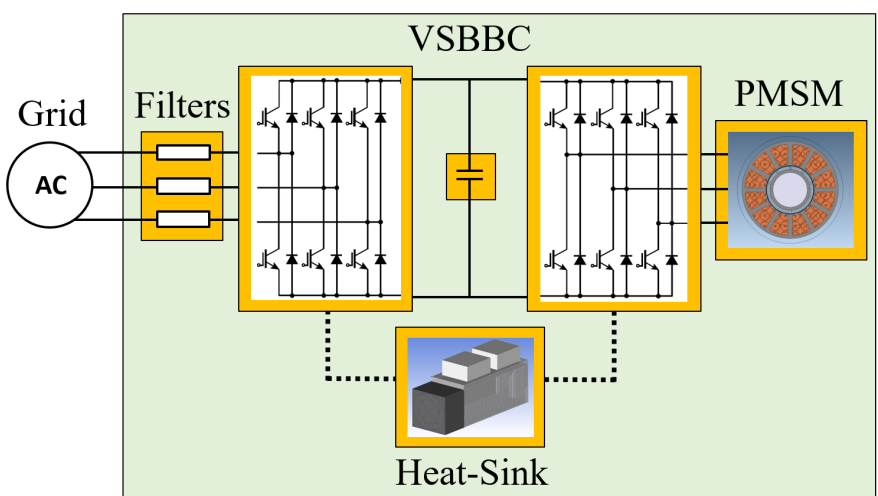

Fig. 2. Motor drive topology considered

\section{Considered Motor Drive Topology}

The motor drive application considered is targeted towards driving aerospace electro-mechanical actuators rated between 2 to $5 \mathrm{~kW}$, with a requirement to move a linear load between two points periodically.

The topology considered is commonly used in industry (as seen in Figure 2). A Voltage-Sourced Back-to-Back Converter (VSBBC) with forced-air convection cooling regulates power from a 3-phase AC grid and drives a PMSM for mechanical output.

Insulated Gate Bipolar Transistor (IGBT) packaged in sixpack modules are considered for good heat dissipation and compactness. It is also assumed that regenerative power from the electrical machine have negligible impact on the grid. No extra braking circuitry is hence considered at the DC-link.

\section{Motor Drive Design Procedure}

In this section, the integrated motor drive design procedure is presented. The process is carried out following the main steps summarized in Figure 3. For sake of clarity, the figure does not show the embedded iterations within the main steps. The iteration parameters are set as a trade-off between evaluation time and convergence tolerance.

\begin{tabular}{|c|}
\hline System \& Load Requirements \\
\hline Electrical Machine sizing \\
\hline Converter Control Analysis \\
\hline Grid Filter Sizing \\
\hline DC-link Capacitor Sizing \\
\hline Converter Loss \& Thermal Analysis \\
\hline C \\
\hline Converter Heat-sink Sizing \\
\hline System Total Weight Evaluation \\
\hline
\end{tabular}

Fig. 3. Motor drive design procedure

This design procedure forms the main objective function to the optimizations discussed in Section IV. Due to paper length constraints, only sizing functions for the three main
TABLE I. Sizing Model InPUT AND OUtPut

\begin{tabular}{|c||c|}
\hline Model Input & Model Output \\
\hline Machine rotor air-gap diameter & Machine peak \& rated output torque \\
Machine length-diameter ratio & Machine torque ripples \\
Machine stator slot opening & Machine rated power factor \\
Machine stator tooth-tips height & Machine copper and iron loss \\
Machine flux density limits & Grid current Total Harmonic Distortion (THD) \\
Max grid current ripple peak-peak & Filter copper and iron loss \\
Converter DC-link voltage & Converter rated modulation indices \\
Converter DC-link capacitance & Converter conduction \& switching losses \\
Converter Switching frequency & Converter DC-link current ripples \\
& Device steady-state temperatures \\
& Machine, Filter \& Heat-sink dimensions \\
\hline
\end{tabular}

weight contributors of a motor drive (electrical machine, gridside boost inductors and converter heat-sink) are presented in this paper. From customer given system constraints, the sizing function input/output are defined according to Table I. The sizing function gives a prediction regarding the motor drive performance along with the physical dimensions. In particular, the physical dimensions of machine, filters and heat-sink are used for the weight evaluation.

In the converter control analysis (not discussed in further sections), rated and peak modulation indices, filter inductances and DC-link capacitance for required steady-state and transient performance are determined.

\section{A. Electrical Machine Sizing Function}

The first main weight contributor considered is the electrical machine, which is fixed as a 12-slot, 10-pole double-layer concentrated winding surface mounted PMSM. The selected pole-slot combination results from previous trade-off studies not detailed in this publication for sake of brevity. The core of this function lies within the application of a few fundamental physics law.

Based on an empirical approximation of the air-gap magnetic flux density and Faraday's induction law (seen in 1), the minimum number of turns required to provide the machine back Electro-Motive Force (EMF) at the desired output speed can be computed.

$$
\oint E \cdot \mathrm{d} l=-N \frac{\mathrm{d}}{\mathrm{d} t} \int_{S} B \cdot \mathrm{d} S=-N \frac{\mathrm{d} \Phi}{\mathrm{d} t}
$$

where $E$ denotes the induced back-EMF in a winding with $N$ turns and $B$ is the density of the magnetic flux $\Phi$ passing through an area of $S$.

Based on an initial estimate of machine power factor and efficiency, and the principle of energy conservation (2), the stator current required to produce the desired torque can similarly be computed.

$$
\mathrm{d} W_{e l}=e i \mathrm{~d} t=\mathrm{d} W_{m e c}+\mathrm{d} W_{\Phi}
$$

where $W_{e l}$ denotes electrical energy determined by an integrated product of voltage $e$ and current $i$ over time $t, W_{m e c}$ 
represents the energy converted to mechanical work and $W_{\Phi}$ is the energy stored in the machine air-gap.

Considering the above formulas, the machine geometry can be determined once flux and current density are defined. In particular, the flux density is selected by taking into consideration the B-H curve of the magnetic material, in order to avoid magnetic saturation. On the other hand, the current density is chosen according to the thermal limit of the adopted insulation material.

Finally, considering the current linkage and magnetic voltages of the main magnetic path (determined by the stator and rotor geometry) and based on Maxwell-Ampere's law (3), the required Permanent Magnet (PM) height can be computed.

$$
\oint H \cdot \mathrm{d} l=\int_{A} J \cdot \mathrm{d} A=\sum i(t)=\Theta
$$

where $H$ denotes the magnetic field strength along an enclosed path with length $l, J$ represents the current density of current $i$ flowing through a cross-sectional area of $A$ and $\Theta$ is the current linkage.

With the newly defined PM height, the magnetic flux leakage (using [10]) and an effective PM width $\alpha$ can be approximated. A new air-gap magnetic flux density can then be calculated and fed back to (1) for computation of the required number of turns. This forms the first iteration loop. Similarly, for the new machine geometry, losses and total inductance can be estimated according to [11]. A new value for power factor and efficiency can also be calculated and fed back to (2) for computation of the required stator current. This thus forms the second iteration loop in this procedure.

The first iteration loop considers variations in effective PM width in relation to PM height, and the second loop considers variations in required stator current in relation to the machine loss and inductance. Constraints and limits are set in place to stop un-converging iterations.

In most existing literature for machine optimization, PM height and number of turns are considered to be inputs design variables to the sizing function. In contrast, this approach arrives at the minimum PM height and required number of turns through iterations. This results in longer time per design point but it compensates with improved consistency in producing feasible designs and requires fewer design variables as input.

For application in an integrated design environment, the machine back-EMF is constrained by the power converter DClink voltage and the maximum number of turns that can be fitted in the machine slot. Similarly, the flux density limits affect local saturation levels within the stator and rotor body. This influences the machine leakage inductance and subsequently its power factor. For the same output mechanical power, the machine power factor sets the required current levels in the converter and hence its losses.

Finally, to capture even more detailed interactions between machine and power converter, the machine eddy current losses are computed as a function of the modulation index, switching frequency and DC-link voltage of the power converter according to [12].

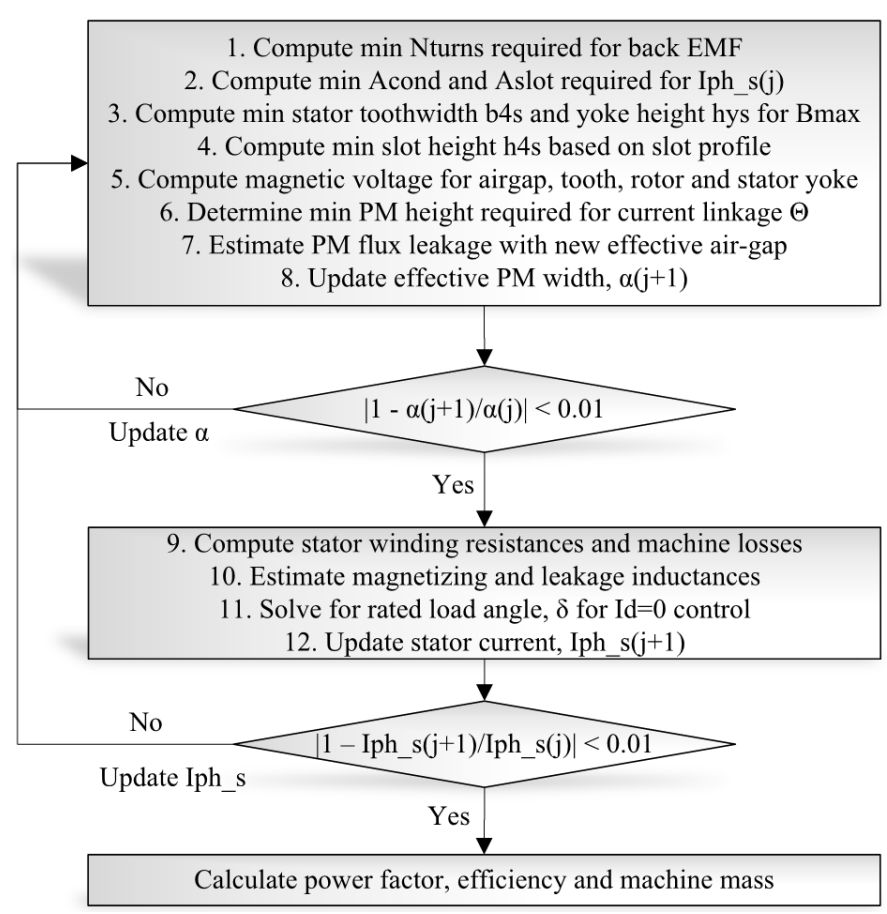

Fig. 4. PMSM sizing function

Figure 4 presents the machine sizing function employed.

\section{B. Grid Filter Sizing Function}

The second main weight contributors of the motor drive considered are the grid side filters. In the sizing function here, only a single stage boost inductor configuration is considered. Toroidal powder cores using magnetic material MPP60 from inductor core manufacturer Magnetics Inc are employed as they have good ac and dc magnetization properties and provide good achievable inductance per volume. The core of this sizing function is again the Maxwell-Ampere's law. According to this law, the closed loop line integral of magnetic field is proportional to current flowing through the loop.

Discrete core sizes and data are first imported from Magnetics Inc to form a selection pool. Given a fixed conductor cross-sectional area and minimum spacing between conductors, the maximum number of turns can be calculated for all core sizes.

Using manufacturer given nominal inductance factors accounting for material saturation limits, the minimum core cross-sectional area and required number of turns for a desired inductance value can be calculated using Maxwell-Ampere's law. Cores unable to meet these requirement can be eliminated from the selection pool.

At rated peak current, the core's permeability drop can be determined based on manufacturer given curves for the chosen magnetic material. The conduction and iron losses causing a core temperature rise can also be estimated using Steinmetz equations. Cores with un-acceptable permeability drops or temperature rise values can hence also be eliminated.

Finally, from the remaining available cores, the smallest core is chosen. Figure 5 shows an efficient implementation 


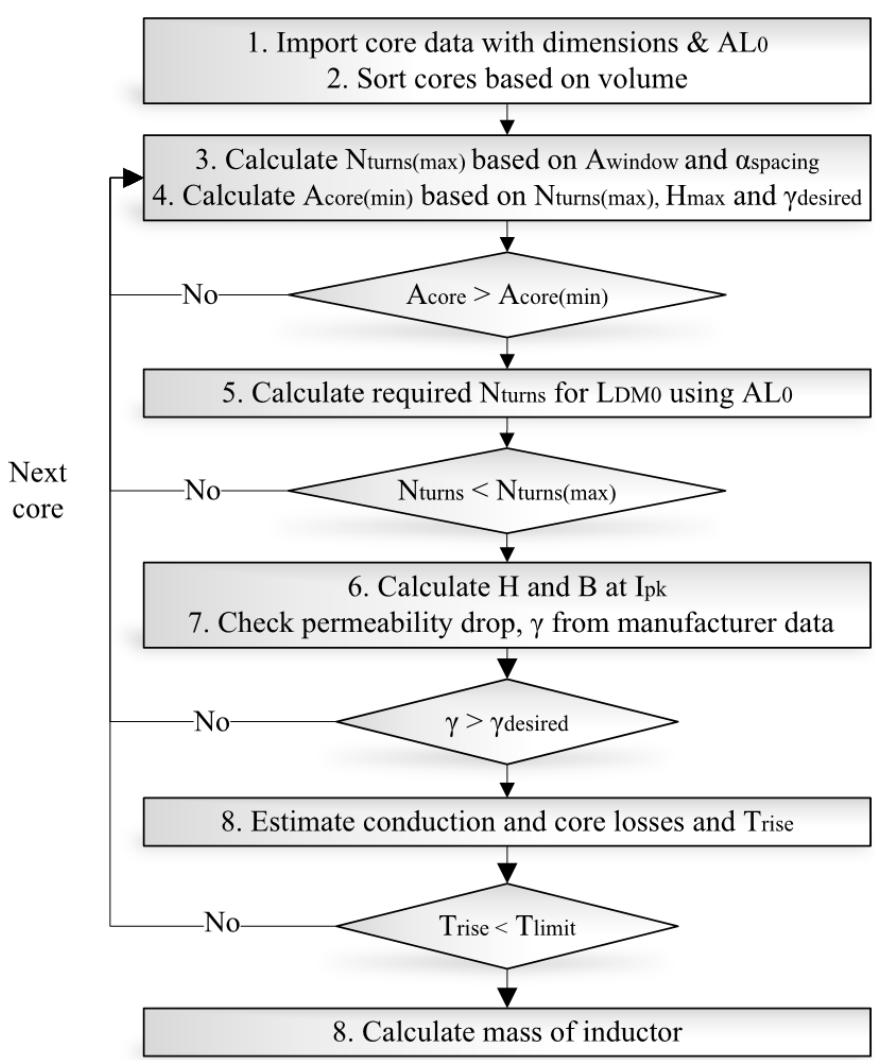

Fig. 5. Inductor sizing function

of this method. Here, the cores are first sorted according to volume. The algorithm then iterates through the selection pool and stops when a suitable core is found.

For fixed power level and power quality requirements expressed in maximum peak-to-peak current ripple, the required grid filter inductance, $L_{\mathrm{b}}$ is a function of the converter switching frequency according to (4).

$$
L_{\mathrm{b}}=\frac{V_{\mathrm{max}}}{f_{\mathrm{sw}} \Delta I_{\mathrm{pp}}}
$$

where $V_{\max }$ denotes the maximum voltage drop across the inductor determined by the converter modulation, $f_{\mathrm{sw}}$ represents the grid side converter's switching frequency and $\Delta I_{\mathrm{pp}}$ is the maximum allowable peak-to-peak current ripple.

After obtaining the filter inductance value, a Finite Fourier Transform (FFT) can be performed on the input current waveform in order to determine the Total Harmonic Distortion. Like the electrical machine, the inductors eddy current losses can be also computed as a function of the power converter modulation index, switching frequency and DC-link voltage according to [13].

\section{Cooling System Sizing Function}

The third main weight contributor of a motor drive is the heat sink used for the IGBT power modules. The heat-sink is assumed to be made of aluminum, with extruded plates. Further, the produced heat is extracted by forced convection by means of a constant-speed fan.

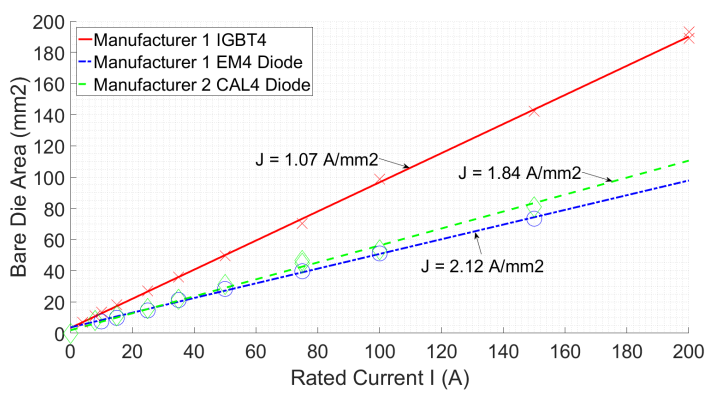

(a)

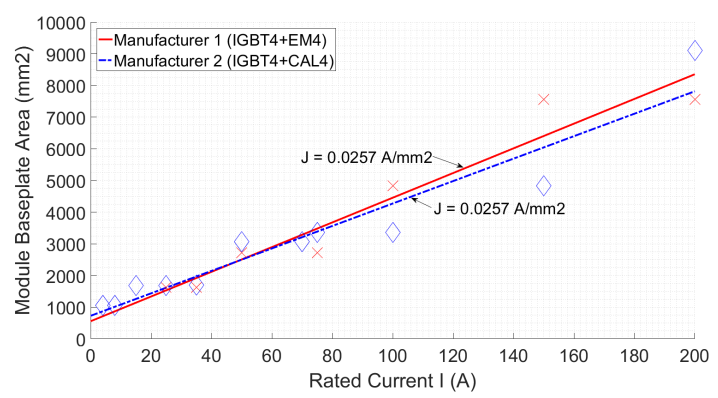

(b)

Fig. 6. Relationship between device current rating and (a) Semiconductor bare-die area (b) Commercially available 6-Pack module base-plate area

Semiconductor losses are inherently a function of the device junction temperature, as expressed in 5 and 6 .

$$
\begin{gathered}
P_{\text {cond }}\left(T_{\mathrm{j}}\right)=U_{\mathrm{f}}\left(T_{\mathrm{j}}\right) * I_{\mathrm{ave}}+R_{\mathrm{f}}\left(T_{\mathrm{j}}\right) * I_{\mathrm{rms}}^{2} \\
P_{\mathrm{sw}}\left(T_{\mathrm{j}}\right)=f_{\mathrm{sw}} * E_{\text {total }}\left(T_{\mathrm{j}}\right)
\end{gathered}
$$

where $P_{\text {cond }}$ denotes the conduction losses, $P_{\mathrm{sw}}$ represents the switching losses, $U_{\mathrm{f}}$ is the IGBT/diode forward voltage, $R_{\mathrm{f}}$ is the IGBT/diode forward resistance, $I$ is the current flowing through the device and $T_{\mathrm{j}}$ is the IGBT/diode junction temperature.

For a representative relationship between converter losses and the required heat-sink size, a non-conventional approach is considered in this sizing function. For a maximum semiconductor chip current density and junction temperature, the minimum required chip area is varied as a function of the predicted losses.

Based on a statistical analysis of chip and power module data from manufacturers, the relationship between chip area and conduction losses, switching losses and junction to heatsink thermal resistance was derived in [14]. Similarly, a relationship between chip area and minimum base-plate area when implemented as a 6-pack module can be derived as seen in Figure 6.

To begin the sizing function, an initial minimum chip area is calculated based on a fixed chip current density value. The corresponding chip properties and minimum base-plate area can then be estimated using the relationships above. From this minimum base-plate area and a standard module widthlength ratio, the heat-sink cooling surface dimensions and 
the minimum achievable heat-sink thermal resistance can be calculated using equations from [15].

With losses and thermal resistance values given as a function of chip area, an iterative process can be employed to determine the steady state losses and chip temperature. If chip temperature exceeds the allowable limits, the chip area is increased and the process is repeated. After several iterations, when chip temperature no longer exceeds the limits, the heatsink weight is given as output as it corresponds to the minimum cooling surface and minimum required chip area.

The other assumptions made by using this method are:

- Uni-directional heat flow from the chip junction through multiple layers like the device substrate and base-plate to heat-sink.

- Continuous range of chip areas available from chip manufacturers.

\section{Multi-LEVEl Optimization}

In this section, a multi-level optimization method is proposed and applied for both designing and optimizing a $3.3 \mathrm{~kW}$ motor drive.

\section{A. Particle Swarm Optimization}

PSO is a random heuristic algorithm that was inspired by the social behavior of animals such as bird flocking. The algorithm starts with a random population matrix of 'particles' which move about a cost function surface with a velocity. Their velocities and positions are then continuously updated based on local and global best solutions until a maximum number of iterations is reached. It is easy to implement, has good performance in terms of computational efficiency and has lower performance degrading with small population sizes [16] [17]. It is therefore selected in this work for optimizing the whole motor drive and its implementation is carried out using the MATLAB global optimization toolbox.

\section{B. Proposed Multi-level Optimization Method}

According to the 4-level modeling paradigm shown in Figure 1 , the model outputs listed in Table I can be grouped into different levels based on their dynamic frequency. Likewise, design variables can be assigned to different levels according to their impact or relevance on the model outputs. For this reason, certain design variables like DC-link voltage could be assigned to multiple levels. The adopted assignment of the design variables is reported below:

1) Component level (above $100 \mathrm{kHz}$ ):

This level models very high frequency behaviors where Electro-Magnetic Interference (EMI) performance of the system are the outputs considered. Design variables assigned to this level include the converter switching frequency, grid filter inductance and converter DC-link voltage.

2) Behavioral level (between $10 \mathrm{kHz}$ and $100 \mathrm{kHz}$ ): This level models high frequency behaviors where eddy current losses in the machine and filters, converter input current ripples, DC-link current ripples and device instantaneous switching losses are the outputs considered. Design variables assigned to this level include the converter switching frequency, grid filter inductance and converter DC-link voltage.

3) Functional level (between $10 \mathrm{~Hz}$ and $10 \mathrm{kHz}$ ): This level models low frequency behaviors, which range includes the machine and grids' fundamental frequency. For the machine: electromagnetic torque, torque ripples, winding losses and hysteresis losses are the outputs considered. For the converters and grid filters: the device instantaneous conduction losses are the outputs considered. Design variables assigned to this level include the machine diameter at rotor air-gap side, stator flux density limits and stator slot dimensions and converter DC-link voltage.

\section{4) Architectural level (below $10 \mathrm{~Hz}$ ):}

This level models steady-state behaviors or isolated events like system start-up and worst-case transient scenarios. The device junction steady-state temperatures, machine peak torque and maximum DC-link voltage transients are the outputs considered. Design variables assigned to this level include the machine diameter at rotor air-gap side, machine lengthdiameter ratio and converter DC-link capacitance.

In contrast with a traditional single-level optimization where all design variables are optimized together, the multilevel approach separates the optimization into several runs with fewer design variables per run. Upon completion of each run, the optimized design variables are fed into next level for a new and independent optimization run. They are then fixed as system parameters for the next run if they are not assigned as design variables. This process is repeated iteratively until no further improvement in objective function is obtained.

The benefits of a multi-level optimization include improved efficiency, increased robustness and faster convergence since the search-space is reduced by several dimensions. However the drawback is that there is increased overhead due to the increased number of independent optimization runs. For instance, the initial search-space needs to be populated several times with the multi-level approach. There is also increased risk of converging at local minimums as design variables are fixed within different optimization runs.

\section{Example: Multi-level Optimization for $3.3 \mathrm{~kW}$ Motor Drive}

In this case study, a $3.3 \mathrm{~kW}$ motor drive system is optimized for weight. The system constraints are listed Table II. Design points are considered invalid if they result in outputs that violate the constraints. Only the top three levels of the modeling paradigm are used within this optimization. To include the component level for EMI performance, detailed EMI models will also need to be included and they are currently out of scope in this work.

Only single-iteration multi-level optimizations are performed in this example. The chosen design variable and PSO parameters for each levels can be seen in Table III. For a fair comparison, the swarm populations for both methods are kept the same at 100 particles. 
The computations are performed using an Intel(R) Core(TM) i7-4770S CPU @ $3.10 \mathrm{GHz}$ with $8.00 \mathrm{~GB}$ of installed RAM. 10 independent runs are performed for both multi- and single-level method and the results are shown in Table IV. Their performances are evaluated in terms of objective function and average computational time. Figure 7 shows the results for the 10 independent runs of the two optimization methods.

The preliminary results suggest that the multi-level optimization is, as expected, more consistent in converging to a good objective function. It is also found to have significantly faster convergence speed as compared to the single-level optimization. However, out of 20 independent runs, it was single-level optimization that converged at the best design point found. This indicates that the multi-level optimization might have missed that point because it consistently converges towards the same local minimum points. The difference between the best design points from single-level and multi-level optimization is however minimal considering the significantly lower average computational time.

TABLE II. STUdy CASE Constraints AND REQUiREMENTS

\begin{tabular}{|c|c|}
\hline Fixed Constraint & Limits \\
\hline Rated speed & $2000 \mathrm{RPM}$ \\
Continuous Torque & $15.86 \mathrm{Nm}$ \\
Acceleration (Peak) Torque & $\geq 58.73 \mathrm{Nm}$ \\
Grid current THD & $\leq 15 \%$ \\
Machine efficiency & $\geq 90 \%$ \\
Converter efficiency & $\geq 90 \%$ \\
\hline
\end{tabular}

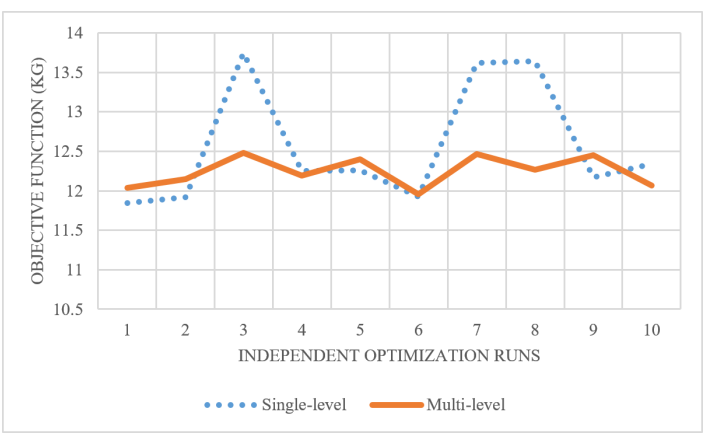

(a)

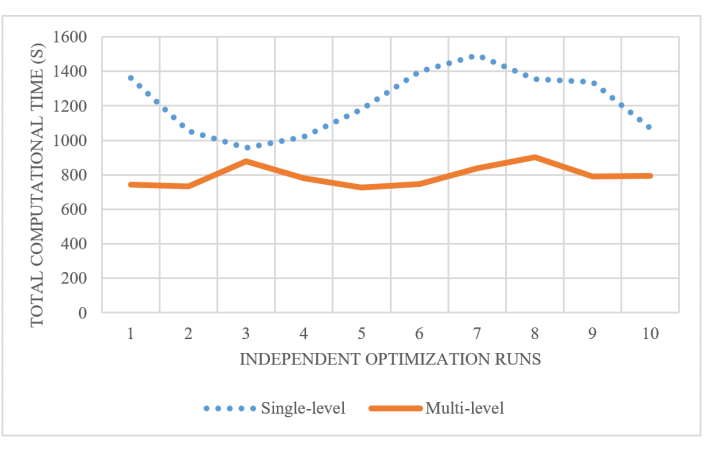

(b)

Fig. 7. Comparison of single-level optimizations against multi-level optimizations (a) Objective function (weight in $\mathrm{kg}$ ) (b) Total computational time (s)
TABLE III. MULTI-LEVEL OPTIMIZATION SETUP

\begin{tabular}{|c|ccc|c|}
\hline \multirow{2}{*}{ Design Variables } & \multicolumn{3}{|c|}{ Multi-level } & \multirow{2}{*}{ Single-level } \\
\cline { 2 - 4 } & Arch. & Func. & Bhvl. & \\
\hline Machine rotor air-gap diameter & $\times$ & $\times$ & - & $\times$ \\
Machine length-diameter ratio & $\times$ & - & - & $\times$ \\
Stator tooth flux density limit & - & $\times$ & - & $\times$ \\
Stator slot opening per unit & - & $\times$ & - & $\times$ \\
Stator tooth-tip height & - & $\times$ & - & $\times$ \\
Max input current pk-pk ripple & - & - & $\times$ & $\times$ \\
Converter switching frequency & - & - & $\times$ & $\times$ \\
Converter DC-link voltage & - & $\times$ & $\times$ & $\times$ \\
\hline \multirow{2}{*}{ PSO parameters } & \multicolumn{3}{|c|}{ Multi-level } & \multirow{2}{*}{ Single-level } \\
\cline { 2 - 4 } & Arch. & Func. & Bhvl. & \\
\hline Number of design variables & 2 & 5 & 3 & 8 \\
Number of iterations & 20 & 20 & 20 & 20 \\
Swarm population & 20 & 50 & 30 & 100 \\
\hline
\end{tabular}

TABLE IV. OPTIMIZATION RESULTS

\begin{tabular}{|c|c|c|}
\hline Optimization Results & Multi-level & Single-level \\
\hline Best objective function $(\mathrm{kg})$ & 11.96 & 11.85 \\
Worst objective function $(\mathrm{kg})$ & 12.48 & 13.75 \\
Mean objective function $(\mathrm{kg})$ & 12.25 & 12.57 \\
Average computational time (s) & 793.34 & 1223.1 \\
\hline
\end{tabular}

\section{Software Validation of Sizing Functions}

The extent of usefulness of practical system optimizations is strongly dependent on the models employed within it. To validate the sizing functions of Section III, several multiphysics software are employed to evaluate the performance of the motor drive designed using the optimization tool.

Infolytica Magnet was employed to perform electromagnetic 2D finite element analysis (FEA) and the geometry obtained from the sizing function was used. M270-35A steel is used for stator and rotor core in this validation. The finite element results for an optimally designed machine at noload and full-load are shown in Figure 8. A good match for the continuous torque values of within $5 \%$ is obtained with predictions from the sizing function.

On the other hand, a steady-state time domain simulation using PLECS was performed to verify grid current THD and worst case current ripples to ensure that the maximum allowable limits are met. The results can be seen in Figure 9. The analytical predictions for input current THD is $14.38 \%$ and the time domain simulations give a THD value of $14.55 \%$.

Finally, to ensure that the heat-sink design meets the thermal resistance requirements, ANSYS Icepak was used to perform a simple thermal 3-D Finite Element analysis with the given heat-sink dimensions and fan performance curve. As seen in Figure 10, the max junction temperature is $106^{\circ} \mathrm{C}$, with a thermal resistance value of $0.3^{\circ} \mathrm{C} / \mathrm{W}$. The thermal resistance predicted by the analytical sizing function is $0.37^{\circ} \mathrm{C} / \mathrm{W}$. 


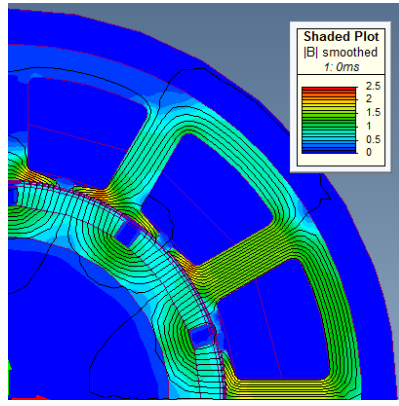

(a)

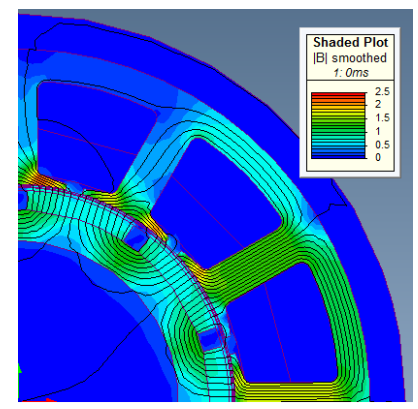

(b)

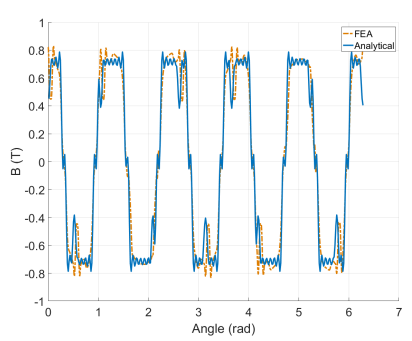

(c)

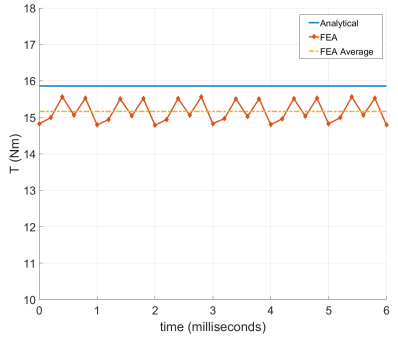

(d)
Fig. 8. Infolytica Magnet Finite Element validation of a 12s/10p PMSM design rated at $3.3 \mathrm{~kW}$ (a) No-load flux density plot (b) Rated load flux density plot (c) No-load air-gap flux density (d) Rated continuous torque

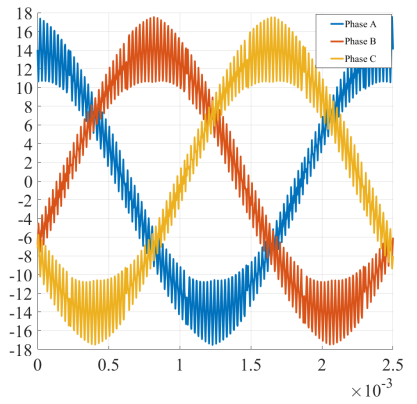

(a)

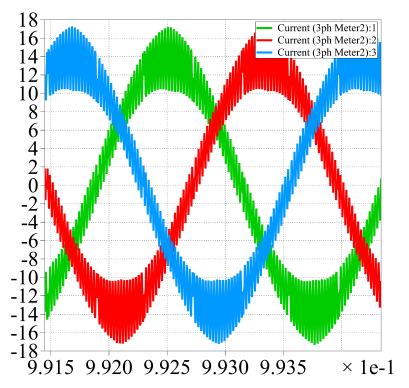

(c)

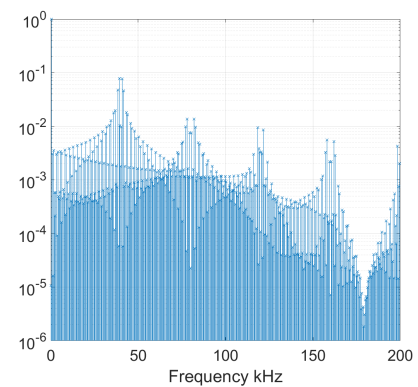

(b)

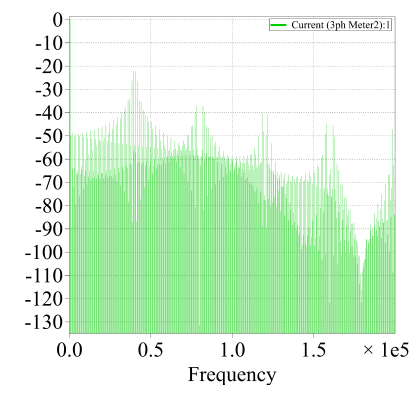

(d)
Fig. 9. Grid input current and FFT (a - b) Analytical sizing function (c - d) PLECS simulation

\section{CONCLUSION}

This paper detailed a motor drive integrated design procedure with a focus on sizing the electrical machine, gridside filters and heat-sink. The procedure is written to be employed in a multi-level optimization based on 4-level modeling paradigms. With this approach, the optimization is separated

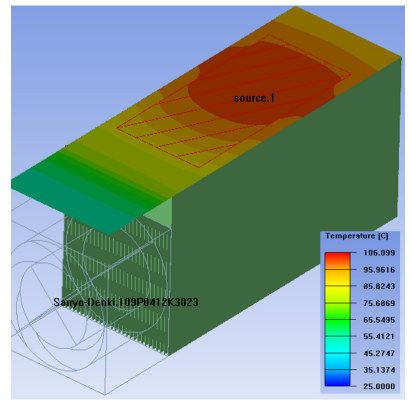

(a)

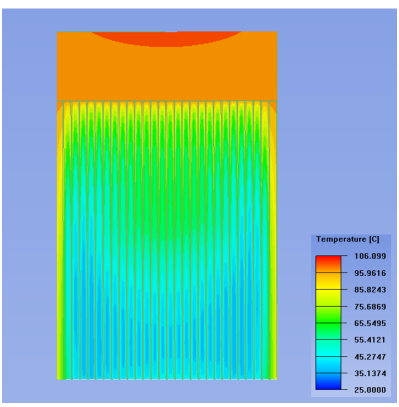

(b)
Fig. 10. Ansys Icepak thermal simulations of converter heat-sink (a) Isometric view (b) Rear-facing view

into levels based on the model output's level of details or dynamic frequency. A case study of a $3.3 \mathrm{~kW}$ motor drive optimization was presented and comparisons were made between the proposed multi-level approach and a more traditional single-level approach. The multi-level method was found to be more consistent in terms of its ability to find minimum points and takes significantly less time to complete. Finally, the paper presented software validations for the sizing functions using multi-physics software. It is important to continuously validate these functions as once again, the extent of usefulness of an optimization is strongly dependent on the models validity.

\section{REFERENCES}

[1] J. A. Rosero, J. A. Ortega, E. Aldabas, and L. Romeral, "Moving towards a more electric aircraft," IEEE Aerospace and Electronic Systems Magazine, vol. 22, no. 3, pp. 3-9, March 2007.

[2] B. Wen, X. Zhang, F. Effah, A. Baraston, P. Zanchetta, D. Boroyevich, J.-L. Schanen, B. Rolando, P. Wheeler, and A. Tardy, "Integrated Design by Optimization of Electrical Power Systems for More Electric Aircraft," in MEA 2015, Toulouse, France, Feb. 2015. [Online]. Available: https://hal.archives-ouvertes.fr/hal-01115434

[3] Y. Duan and D. M. Ionel, "A review of recent developments in electrical machine design optimization methods with a permanentmagnet synchronous motor benchmark study," IEEE Transactions on Industry Applications, vol. 49, no. 3, pp. 1268-1275, May 2013.

[4] I. Laird, X. Yuan, J. Scoltock, and A. Forsyth, "A design optimisation tool for maximising the power density of 3-phase dc-ac converters using silicon carbide (sic) devices," IEEE Transactions on Power Electronics, vol. PP, no. 99, pp. 1-1, 2017.

[5] Q. Wang, X. Zhang, R. Burgos, D. Boroyevich, A. White, and M. Kheraluwala, "Design and optimization of a high performance isolated three phase ac/dc converter," in 2016 IEEE Energy Conversion Congress and Exposition (ECCE), Sept 2016, pp. 1-10.

[6] J. Wang and D. Howe, "Design optimization of radially magnetized, iron-cored, tubular permanent-magnet machines and drive systems," IEEE Transactions on Magnetics, vol. 40, no. 5, pp. 3262-3277, Sept 2004.

[7] M. Rottach, C. Gerada, and P. W. Wheeler, "Design optimisation of a fault-tolerant pm motor drive for an aerospace actuation application," in 7th IET International Conference on Power Electronics, Machines and Drives (PEMD 2014), April 2014, pp. 1-6.

[8] H. Ounis, B. Sareni, X. Roboam, and A. D. Andrade, "Multi-level integrated optimal design for power systems of more electric aircraft," Mathematics and Computers in Simulation, vol. 130, pp. 223 - 235, 2016, 11th International Conference on Modeling and Simulation of Electric Machines, Converters and Systems. [Online]. Available: http://www.sciencedirect.com/science/article/pii/S0378475415001810

[9] P. Wheeler and S. Bozhko, "The more electric aircraft: Technology and challenges." IEEE Electrification Magazine, vol. 2, no. 4, pp. 6-12, Dec 2014. 
[10] Z. Q. Zhu, D. Howe, and C. C. Chan, "Improved analytical model for predicting the magnetic field distribution in brushless permanentmagnet machines," IEEE Transactions on Magnetics, vol. 38, no. 1, pp. 229-238, Jan 2002.

[11] J. P. T. J. V. Hrabovcova, Design of Rotating Electrical Machines (2nd edition). John Wiley \& Sons, Ltd, 2014.

[12] R. Liu, C. C. Mi, and D. W. Gao, "Modeling of iron losses of electrical machines and transformers fed by pwm inverters," in 2007 IEEE Power Engineering Society General Meeting, June 2007, pp. 1-7.

[13] J. Muhlethaler, J. Biela, J. W. Kolar, and A. Ecklebe, "Improved coreloss calculation for magnetic components employed in power electronic systems," IEEE Transactions on Power Electronics, vol. 27, no. 2, pp. 964-973, Feb 2012.

[14] T. Friedli and J. W. Kolar, "A semiconductor area based assessment of ac motor drive converter topologies," in 2009 Twenty-Fourth Annual IEEE Applied Power Electronics Conference and Exposition, Feb 2009, pp. 336-342.

[15] U. Drofenik and J. W. Kolar, "Sub-optimum design of a forced air cooled heat sink for simple manufacturing," in 2007 Power Conversion Conference - Nagoya, April 2007, pp. 1189-1194.

[16] J. Kennedy and R. Eberhart, "Particle swarm optimization," in Neural Networks, 1995. Proceedings., IEEE International Conference on, vol. 4, Nov 1995, pp. 1942-1948 vol.4.

[17] M. Calvini, M. Carpita, A. Formentini, and M. Marchesoni, "Pso-based self-commissioning of electrical motor drives," IEEE Transactions on Industrial Electronics, vol. 62, no. 2, pp. 768-776, Feb 2015. 